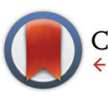

CrossMark \& click for updates

Cite this: Polym. Chem., 2016, 7, 5060

Received 25th May 2016, Accepted 10 th July 2016

DOI: 10.1039/c6py00903d

www.rsc.org/polymers

\section{Ternary organic-inorganic nanostructured hybrid materials by simultaneous twin polymerization $\uparrow$}

\begin{abstract}
J. Weißhuhn, ${ }^{a}$ T. Mark, ${ }^{b}$ M. Martin, ${ }^{a}$ P. Müller, ${ }^{b}$ A. Seifert ${ }^{a}$ and S. Spange ${ }^{\star a}$
The acid and base catalyzed simultaneous twin polymerization (STP) of various 2,2'-disubstituted $4 \mathrm{H}$ 1,3,2-benzodioxasiline derivatives $\mathbf{2} \mathbf{a}$ - $\mathbf{d}$ with $\mathbf{2}, \mathbf{2}^{\prime}$-spirobi[4H-1,3,2-benzodioxasiline] (1) are presented in this paper. The products are nanostructured ternary organic-inorganic hybrid materials consisting of a cross-linked organic polymer, silica and a disubstituted polysiloxane. It can be demonstrated whether and in which extent the copolymerization of the two inorganic fragments of $\mathbf{1}$ and $\mathbf{2}$ takes place among the STP and how the molar ratio of the two components determines the structure formation of the resulting hybrid material. Steric and electronic effects of the substituents at the silicon center of $\mathbf{2}$ on the molecular structure formation and the morphology of the resulting hybrid material were investigated by means of solid state CP MAS ${ }^{29} \mathrm{Si}$ and ${ }^{13} \mathrm{C}$ NMR spectroscopy as well as high-angle annular dark-field scanning transmission electron microscopy (HAADF-STEM). The mechanical properties (hardness and Young's modulus) of the hybrid materials were analyzed by means of nanoindentation measurements.
\end{abstract}

\section{Introduction}

The fabrication of organic-inorganic hybrid materials has been reported for a variety of material combinations. Hybrid materials can be classified by different categories such as molecular composition, morphology, geometry of internal assembly of the components, external shape, or size. ${ }^{1-3}$ Therefore, the diversity of possibilities of organic-inorganic hybrid material makes the nomenclature difficult. ${ }^{4}$ According to Sanchez, they can be classified in terms of the nature of the bonds between the organic and the inorganic phase. Class I hybrid materials have only weak bonds (hydrogen, van der Waals or ionic bonds) between the organic and the inorganic compound, whereas in class II materials both phases are connected by covalent bonds. ${ }^{5}$

The synthesis of organic-inorganic hybrid materials containing two different polymers can be carried out by three different strategies: simultaneous polymerization of two different monomers ${ }^{6-8}$ (SP), polymerization of heterobifunctional monomers ${ }^{9,12,13}$ (HP) and twin polymerization ${ }^{10,11}$ (TP).

The twin polymerization is based on single source monomers which combine an organic moiety directly connected to an inorganic one by covalent bonds. The twin monomer

\footnotetext{
${ }^{a}$ Department of Polymer Chemistry, Institute of Chemistry, Technische Universität Chemnitz, Strasse der Nationen 62, D-09111 Chemnitz, Germany. E-mail: Stefan.spange@chemie.tu-chemnitz.de

${ }^{b}$ BASF SE, Carl-Bosch Strasse 38, D-67056 Ludwigshafen, Germany

$\dagger$ Electronic supplementary information (ESI) available. See DOI: 10.1039/c6py00903d
}

undergoes polymerization to a hybrid material which finally consists of an organic and an inorganic polymer. The two polymers are formed in one mechanistically coupled process either through acid or base catalysis or simply by thermal treatment. If phase separation can be avoided, the resulting polymers form interpenetrating networks. The nature of the catalyst, the molecular structure of the twin monomer used and the turnover of the reaction determine whether a class I or class II hybrid-material is obtained and thus the physical properties thereof. ${ }^{10,11}$

Hybrid materials derived from TP are not limited to the formation of only two polymers. TP also provides an elegant strategy to generate more than two polymers in one procedure by simple mixing of more than one kind of TM and polymerize them to an organic-inorganic hybrid material using the simultaneous TP (STP). ${ }^{14}$ If twin monomers with the same organic fragment are combined, two theoretically possible scenarios result according to Fig. 1.

2,2'-Spirobi[4H-1,3,2-benzodioxasiline] 1 bases on salicylic alcohol as organic moiety. ${ }^{10,11,15}$ It is an ideal twin monomer because polymerization gives phenolic resin and silica without the formation of low molecular weight condensation byproducts. The exchange of one unit of salicylic alcohol provides a variety of different monomer structures. The objective of this work is the study of the STP of various 2,2'-disubstituted 4H-1,3,2-benzodioxasiline derivatives 2 a-d with 1 (Scheme 1).

The twin polymerization of monomer 1 has been well documented in the literature. ${ }^{16-19}$ Thermal polymerization, acid or base catalysis is possible to achieve product formation. The STP of 1 and 2 can produce ternary organic-inorganic hybrid 
classification with identical structural organic units

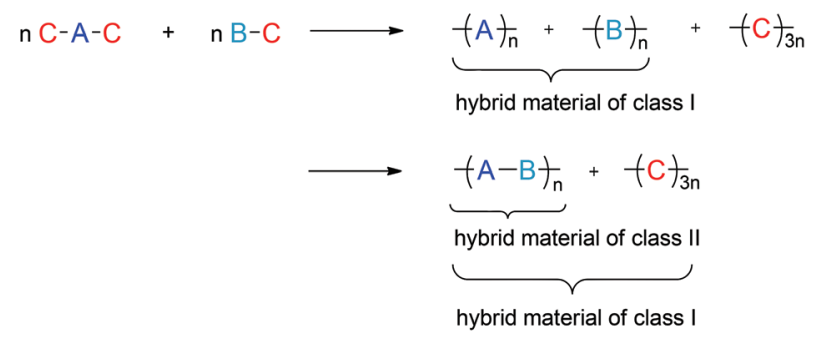

A, B: inorganic part $\quad C$ : organic part

Fig. 1 Theoretical scenarios and assumed classification of the composition of ternary organic-inorganic hybrid materials obtained by STP of the monomers $\mathrm{C}-\mathrm{A}-\mathrm{C}$ and $\mathrm{B}-\mathrm{C}$. $\mathrm{C}$ is the identical structural organic unit in each of the twin monomers. ${ }^{14}$

materials consisting of a cross-linked organic polymer, silica, and a disubstituted polysiloxane. Silica formed during TP of 1 builds a rigid inorganic network. TP of monomers $2 \mathbf{a}-\mathbf{d}$ theoretically produces a hybrid material consisting of a polysiloxane as an inorganic polymer and phenolic resin as an organic polymer (Scheme 1). Polysiloxanes as components in hybrid materials have been studied and widely used in industrial fields for many years. ${ }^{20}$ They are known for their low glass transition temperatures $\left(T_{\mathrm{g}}\right)$ due to the long $\mathrm{Si}-\mathrm{O}$ bond and wide $\mathrm{O}-\mathrm{Si}-\mathrm{O}$ bond angle. The glass transition temperature of polydimethylsiloxane (PDMS) is $-123{ }^{\circ} \mathrm{C} .{ }^{20}$ With an increase in the size of the groups $\mathrm{R}^{1}$ and $\mathrm{R}^{2}$ the $T_{\mathrm{g}}$ also increases, as polymethylphenylsiloxane (PMPS) and polydiphenylsiloxane (PDPS) show glass transition temperatures of $-28{ }^{\circ} \mathrm{C}$ and $40{ }^{\circ} \mathrm{C}$, respectively. ${ }^{20}$ This low temperature elasticity of the inorganic network and the restriction to the formation of linear polymer chains or rings are the main differences to monomer 1. This needs to be considered when investigating the properties of the resulting polymers from STP of 1 and 2. Phenolic resin as an organic polymer is built from both monomers during STP.

In principle, the simultaneous polymerization of the two monomers 1 and 2 can cause different scenarios depending on the inorganic fragment of the monomers which do or do not react with each other to copolymers. According to Sanchez, the different scenarios would result in different classification of the materials (Fig. 1). Especially the mechanical properties could be influenced by the copolymerization of the inorganic fragments. The polysiloxane of monomer 2 can act as internal plasticizer in the hybrid material due to its low glass transition temperatures $\left(T_{\mathrm{g}}\right)$. This covalent linkage is an advantage compared to external plasticizers which can migrate easily and have lower long term stability.

The aim of this study is to analyze whether and in which extent the copolymerization of the two silicon fragments of 1 and 2 takes place among STP and how the molar ratio of the two components affects the overall structure formation and properties of the resulting hybrid material.

\section{Experimental}

\section{Materials and methods}

All solvents were purified and dried by applying standard techniques. The reactions were carried out with freshly distilled, dried solvents and under inert atmosphere. Salicylic alcohol (99\%) was used as purchased from Alfa Aesar. Ethyldichlorosilane (97\%) was used as purchased from TCI. Methylphenyldichlorosilane (98\%) was used as purchased from Fluka. Diphenyldichlorosilane (99\%) and dicyclohexyldichlorosilane (97\%) were used as purchased from ABCR. Triethylamine was used as purchased from Roth.

${ }^{1} \mathrm{H},{ }^{13} \mathrm{C}\left\{{ }^{1} \mathrm{H}\right\}$ and ${ }^{29} \mathrm{Si}\left\{{ }^{1} \mathrm{H}\right\}$ NMR spectra for all compounds were recorded in $\mathrm{CDCl}_{3}$ on a Bruker “Avance DRX 250" (250.1, 63 and $49.7 \mathrm{MHz}$, respectively) operating at room temperature. Chemical shifts $(\delta)$ are reported in parts per million and referenced with the residual undeuterated solvent.

Elemental analyses were determined through a "Vario MICRO" of Elementar Analysensysteme GmbH. Melting point was evaluated using the apparatus "Polytherm A" from WAGNER \& MUNZ. Differential scanning calorimetry curves were recorded on a "DSC 30" from Mettler Toledo in nitrogen atmosphere at a volume flow of $50 \mathrm{~mL} \mathrm{~min}^{-1}$. The measurements were performed at a heating rate of $10 \mathrm{~K} \mathrm{~min}^{-1}$ from 0 to $300{ }^{\circ} \mathrm{C}$ in $40 \mu \mathrm{l}$ closed aluminium crucibles.

Solid state NMR measurements were performed at $9.4 \mathrm{~T}$ on a Bruker Avance 400 spectrometer which were equipped with double-tuned probes capable of MAS (magic angle spinning). The samples were packed in $3.2 \mathrm{~mm}$ rotors made of zirconium oxide spinning at $15\left({ }^{13} \mathrm{C}\right)$ and $12 \mathrm{kHz}\left({ }^{29} \mathrm{Si}\right) .{ }^{13} \mathrm{C}$ - and ${ }^{29} \mathrm{Si}-\left\{{ }^{1} \mathrm{H}\right\}$ CP-MAS-NMR spectra were acquired using cross polarization

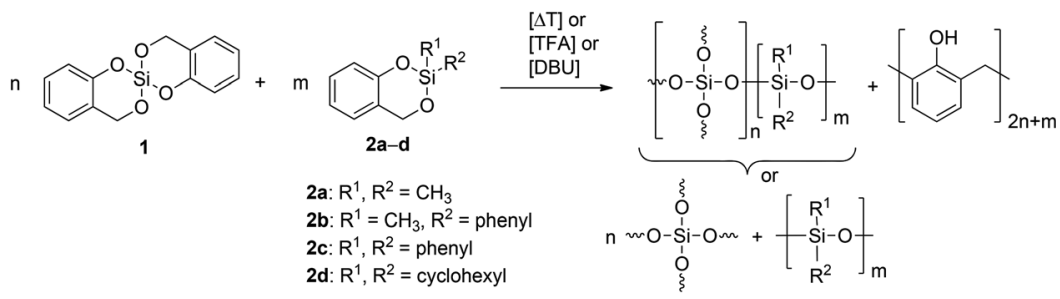

Scheme 1 Suggested scenarios of product formation of the STP of 2,2'-spirobi[4H-1,3,2-benzodioxasiline] 1 with various 2,2-disubstituted $4 H$-1,3,2-benzodioxasilines 2 . 
(CP) technique with contact time of $3 \mathrm{~ms}$ to enhance sensitivity, with a recycle delay of $6 \mathrm{~s}$ and ${ }^{1} \mathrm{H}$ decoupling using a TPPM (two puls phase modulation) puls sequence. The spectra are referenced with respect to tetramethyl silane (TMS) using TTSS (tetrakis(trimethylsilyl)silane) as a secondary standard (3.55 ppm for ${ }^{13} \mathrm{C},-9.5 \mathrm{ppm}$ for ${ }^{29} \mathrm{Si}$ ). If not stated otherwise, all spectra were acquired at room temperature.

In principle, the cross polarization technique used is not quantitative because the efficiency of polarization transfer from ${ }^{1} \mathrm{H}$ to ${ }^{29} \mathrm{Si}$ is different for the different silicon-species, depending on experimental parameters like the contact time. The intensity of NMR-signals of silicon atoms with hydrogen in close proximity (D-species) is enhanced. As a consequence it is not useful to integrate these spectra (D vs. Q) because it will not give the real concentration. However, all measurements were performed under identical experimental conditions. This allows to compare the spectra of the hybrid materials among each other.

Ultra-thin samples for TEM were prepared by Ultramicrotomy. The polymer was therefore embedded in Epofix resin (Struers; Denmark) and cut at room temperature. HAADFSTEM images were recorded on a Tecnai G2-F20ST machine (FEI Company, USA) operated at $200 \mathrm{keV}$. Images were evaluated using the Olympus (Japan) iTEM 5.2 (Build 3554) and FEI TIA 4.1.202 software packages. In the HAADF-STEM images presented in this work, bright contrast corresponds to heavier elements like Si or denser sample regions.

The nanoindentations were conducted using a Nanoindenter UNAT with a Berkovich diamond indenter. The hardness and Young's Modulus were measured using the following experimental parameters: maximum load of $5 \mathrm{mN}$, the holding time was $180 \mathrm{~s}, 18-28$ experiments of indentation were performed for each sample at 18-28 different locations, the average of all measurement for each sample was used. The experiments were carried out at room temperature. The Oliver and Pharr method was employed to extract the mechanical properties using a Poisson's ratio of 0.4.

\section{Synthetic procedures}

General procedure for the synthesis of compound $2 a-d$. A solution of 1 equivalent dichlorodialkylsilane in $70 \mathrm{~mL}$ toluene was slowly added to a stirred solution of 1 equivalent salicylic alcohol and 2 equivalents triethylamine in $200 \mathrm{~mL}$ toluene at $50{ }^{\circ} \mathrm{C}$. The mixture was stirred at $65^{\circ} \mathrm{C}$ for $2 \mathrm{~h}$. The resulting precipitate was removed by filtration under inert conditions. Excess of toluene was removed under reduced pressure. The crude product was purified by distillation (2a: $0.3 \mathrm{mbar} / 50{ }^{\circ} \mathrm{C}$; $2 \mathbf{b}$ : $0.3 \mathrm{mbar} / 130^{\circ} \mathrm{C}$; $2 \mathrm{c}: 0.4 \mathrm{mbar} / 180{ }^{\circ} \mathrm{C}$; $2 \mathrm{~d}$ : $\left.0.15 \mathrm{mbar} / 188^{\circ} \mathrm{C}\right)$.

2-Methyl-2-phenyl-4H-1,3,2-benzodioxasiline (2b). Colorless liquid; Yield: $72 \% ;{ }^{1} \mathrm{H}-\mathrm{NMR}\left(250 \mathrm{MHz}, \mathrm{CDCl}_{3}, 25{ }^{\circ} \mathrm{C}\right): \delta(\mathrm{ppm})$ $=0.64\left(\mathrm{~s}, 3 \mathrm{H}, \mathrm{CH}_{3}\right), 5.05\left(\mathrm{~s}, 2 \mathrm{H}, \mathrm{Ar}-\mathrm{CH}_{2}\right), 6.93-7.05(\mathrm{~m}, 3 \mathrm{H}, \mathrm{Ar}-$ H), 7.22-7.27 (m, 1H, Ar-H), 7.38-7.42 (m, 3H, Ar-H), 7.67-771 (m, 2H, Ar-H); ${ }^{13} \mathrm{C}-\left\{{ }^{1} \mathrm{H}\right\}-\mathrm{NMR}\left(63 \mathrm{MHz}, \mathrm{CDCl}_{3}, 25{ }^{\circ} \mathrm{C}, \mathrm{TMS}\right)$ : $\delta(\mathrm{ppm})=-3.0\left(\mathrm{CH}_{3}\right), 64.3\left(\mathrm{Ar}-\mathrm{CH}_{2}\right), 119.5(\mathrm{Ar}), 121.3(\mathrm{Ar})$, 126.3 (Ar), 127.1 (Ar), 128.2 (Ar), 129.1 (Ar), 131.0 (Ar), 133.6
(Ar), 133.8 (Ar), $153.3(\mathrm{Ar}) ;{ }^{29} \mathrm{Si}-\left\{{ }^{1} \mathrm{H}\right\}-\mathrm{NMR}$ (49.7 MHz, $\mathrm{CDCl}_{3}$, $25{ }^{\circ} \mathrm{C}$, TTMSS): $\delta(\mathrm{ppm})=-10.9$; ATR-FT-IR: $\tilde{\nu}\left(\mathrm{cm}^{-1}\right)=3023$, 2961, 1607, 1485, 1275, 1125, 1030, 912, 830; EA: Calc. for $\mathrm{C}_{14} \mathrm{H}_{14} \mathrm{O}_{2} \mathrm{Si}$ (242.35): C 69.38, H 5.82; Found: C 69.20, H 5.93.

2,2-Diphenyl-4H-1,3,2-benzodioxasiline (2c). Colorless solid; Yield: $86 \% ; T_{\mathrm{mp}}=73-75{ }^{\circ} \mathrm{C} ;{ }^{1} \mathrm{H}-\mathrm{NMR}\left(250 \mathrm{MHz}, \mathrm{CDCl}_{3}, 25{ }^{\circ} \mathrm{C}\right)$ : $\delta(\mathrm{ppm})=5.12\left(\mathrm{~s}, 2 \mathrm{H}, \mathrm{Ar}-\mathrm{CH}_{2}\right), 6.92-7.06(\mathrm{~m}, 3 \mathrm{H}, \mathrm{Ar}-\mathrm{H})$, 7.20-7.27 (m, 1H, Ar-H), 7.38-7.54 (m, 6H, Ar-H), 7.72-7.75 (m, 4H, Ar-H); ${ }^{13} \mathrm{C}-\left\{{ }^{1} \mathrm{H}\right\}-\mathrm{NMR}\left(63 \mathrm{MHz}, \mathrm{CDCl}_{3}, 25{ }^{\circ} \mathrm{C}, \mathrm{TMS}\right)$ : $\delta(\mathrm{ppm})=64.7\left(\mathrm{Ar}-\mathrm{CH}_{2}\right), 119.7(\mathrm{Ar}), 121.5(\mathrm{Ar}), 126.4(\mathrm{Ar})$, 127.2 (Ar), 128.2 (Ar), 129.2 (Ar), 131.3 (Ar), 131.4 (Ar), 134.9 (Ar), 153.4 (Ar); ${ }^{29} \mathrm{Si}-\left\{{ }^{1} \mathrm{H}\right\}-\mathrm{NMR}\left(49.7 \mathrm{MHz}, \mathrm{CDCl}_{3}, 25{ }^{\circ} \mathrm{C}\right.$, TTMSS): $\delta(\mathrm{ppm})=-26.7$; ATR-FT-IR: $\tilde{\nu}\left(\mathrm{cm}^{-1}\right)=3034,2967$, 1607, 1485, 1252, 1117, 1022, 910, 695; EA: Calc. for $\mathrm{C}_{19} \mathrm{H}_{16} \mathrm{O}_{2} \mathrm{Si}$ (304.42): C 74.96, H 5.30; Found: C 74.97, H 5.33.

2,2-Dicyclohexyl-4H-1,3,2-benzodioxasiline (2d). Yellow liquid; Yield: $81 \%$; ${ }^{1} \mathrm{H}-\mathrm{NMR}\left(250 \mathrm{MHz}, \mathrm{CDCl}_{3}, 25{ }^{\circ} \mathrm{C}\right): \delta(\mathrm{ppm})$ $=0.92-1.02(\mathrm{~m}, 2 \mathrm{H}, \mathrm{CH}), 1.21-1.33\left(\mathrm{~m}, 10 \mathrm{H}, \mathrm{H}_{\mathrm{ax}}\right), 1.69-1.78$ $\left(\mathrm{m}, 10 \mathrm{H}, \mathrm{H}_{\text {equ }}\right), 4.95$ (s, 2H, Ar- $\left.\mathrm{CH}_{2}\right), 6.86-6.97$ (m, 3H, Ar-H), 7.15-7.21 (m, 1H, Ar-H); ${ }^{13} \mathrm{C}-\left\{{ }^{1} \mathrm{H}\right\}-\mathrm{NMR}\left(63 \mathrm{MHz}, \mathrm{CDCl}_{3}, 25{ }^{\circ} \mathrm{C}\right.$, TMS): $\delta(\mathrm{ppm})=24.7(\mathrm{CH}), 26.3\left(\mathrm{CH}_{2}\right), 26.4\left(\mathrm{CH}_{2}\right), 26.8\left(\mathrm{CH}_{2}\right)$, $27.7\left(\mathrm{CH}_{2}\right), 65.0\left(\mathrm{Ar}-\mathrm{CH}_{2}\right), 119.3(\mathrm{Ar}), 120.8(\mathrm{Ar}), 126.2(\mathrm{Ar})$, 127.5 (Ar), 128.9 (Ar), $154.0(\mathrm{Ar}) ;{ }^{29} \mathrm{Si}-\left\{{ }^{1} \mathrm{H}\right\}-\mathrm{NMR}(49.7 \mathrm{MHz}$, $\mathrm{CDCl}_{3}, 25{ }^{\circ} \mathrm{C}$, TTMSS): $\delta(\mathrm{ppm})=-6.4$; ATR-FT-IR: $\tilde{\nu}\left(\mathrm{cm}^{-1}\right)=$ 3024, 2921, 2666, 1607, 1485, 1275, 1105, 1032, 909, 754; EA: Calc. for $\mathrm{C}_{19} \mathrm{H}_{28} \mathrm{O}_{2} \mathrm{Si}$ (316.51): C 72.10, H 8.92; Found: C 71.59, H 8.99.

\section{Polymerization}

The combination of the desired monomers $\mathbf{1}$ and $\mathbf{2 a - d}$ was mixed and heated at $80{ }^{\circ} \mathrm{C}$ to give a clear melt. After cooling the mixture at room temperature for 5 minutes the catalyst was added. Coloured monolithic polymers are obtained due to the phenolic resin compound. The polymers cooled to room temperature and dried in a desiccator over calcium chloride. In case of the trifluoromethanesulfonic acid (TFA) the temperature was $85{ }^{\circ} \mathrm{C}$ with a monomer/catalyst ratio of $20: 1$. Base catalysis with 1,8-diazabicyclo[5.4.0] undec-7-ene (DBU) used temperatures between 100 to $140{ }^{\circ} \mathrm{C}$ and a monomer/catalyst ratio of $50: 1$ or $100: 1$.

\section{Extraction}

About $1 \mathrm{~g}$ of the resulting powdered polymer material was placed in an extraction thimble $(19 \times 90 \mathrm{~mm})$ of Fischerbrand and soxhlet-extracted with $200 \mathrm{~mL}$ dichloromethane for $30 \mathrm{~h}$. The residue was dried at $40{ }^{\circ} \mathrm{C}$ and $50 \mathrm{mbar}$ until the weight was constant. Excess of dichloromethane was removed under reduced pressure to give the extract.

\section{Results and discussion}

Simultaneous twin polymerization of two monomers - ternary organic-inorganic hybrid materials

The synthesis of the twin monomers $2 \mathbf{a}-\mathbf{d}$ is shown in Scheme 2. Homo twin polymerization of $\mathbf{2 a - d}$ was also per- 


$$
\text { (1) }
$$

2a: $\mathrm{R}^{1}, \mathrm{R}^{2}=\mathrm{CH}_{3}$

2b: $\mathrm{R}^{1}=\mathrm{CH}_{3}, \mathrm{R}^{2}=$ phenyl 2c: $R^{1}, R^{2}=$ phenyl 2d: $R^{1}, R^{2}=$ cyclohexyl

Scheme 2 Molecular structure and synthesis of twin monomers $2 a,{ }^{14,24} 2 b^{25} 2 c^{24}$ and $2 d$.

formed. The base 1,8-diazabicyclo[5.4.0]undec-7-ene (DBU, $\left.\mathrm{p} K_{\mathrm{a}}^{\mathrm{aq}}=13.4, \mathrm{p} K_{\mathrm{a}}^{\mathrm{MeCN}}=24.34\right)^{21,22}$ and the acid trifluoroacetic acid (TFA, $\left.\mathrm{p} K_{\mathrm{a}}^{\mathrm{aq}}=0.0\right)^{23}$ were used as catalysts. The homo twin polymerization of monomer 2 shows high amounts of extractable content, especially concerning the polydialkyl(aryl) siloxane component. Detailed results and discussions can be found in the ESI. $\dagger$ The solubility of the inorganic component of 2 can be prevented by copolymerization with the silicon network derived from 1 . Hence, the acid and base catalyzed STP of 1 and 2 was investigated. To adjust the polymerization temperatures for the STP, the mixtures of monomer 1 and monomer 2 were analysed by DSC measurements. Exothermic peaks in the DSC curves can indicate a polymerization of the monomer due to the heat of polymerization. The results of the DSC measurements of the monomer mixtures as function of type of catalysis are presented in Table 1 . The corresponding DSC curves are shown in the ESI (Fig. S2, S3, S6 and S7†). The onset temperatures for the thermally induced twin polymerization were monitored by exothermic peaks varying between 184 and $219^{\circ} \mathrm{C}$. There is no clear observable trend regarding the molecular structure of monomer 2 . A slightly reduced trigger temperature, compared to pure $\mathbf{1}$, was found only for the mixture of 1 and $2 \mathrm{c}$.

Base catalyzed twin polymerization is readily suitable for all mixtures of monomers 1 and 2, with polymerization temperatures about $107{ }^{\circ} \mathrm{C}$. Herein the combination of both monomers (except 2d) reduces the trigger temperatures, compared to the single monomers 2, when catalyzed with DBU (Fig. S3†).

In comparison to the single monomers 2 with TFA (Fig. S2 $\dagger$ ), the polymerization trigger temperatures of the monomer mixtures with TFA are reduced below $85{ }^{\circ} \mathrm{C}$.

According to the results of the DSC measurement, the polymerization experiments were performed in monomer melt with TFA and DBU at temperatures of $85{ }^{\circ} \mathrm{C}$ and $110{ }^{\circ} \mathrm{C}$, respectively.

Table 1 Characteristic trigger temperatures for the thermally induced, DBU and TFA catalyzed STP of different monomer mixtures of 1 with $2 a-d$ as determined by DSC measurements

\begin{tabular}{llll}
\hline & \multicolumn{3}{l}{$T_{\text {onset, exo }}\left[{ }^{\circ} \mathrm{C}\right]$} \\
\cline { 2 - 4 } Monomer mixture (1:1 w eq. $)$ & Thermally induced & DBU & TFA \\
\hline $\mathbf{1}+\mathbf{2 a}$ & 197 & 130 & 25 \\
$\mathbf{1}+\mathbf{2 b}$ & 219 & 106 & 30 \\
$\mathbf{1}+\mathbf{2 c}$ & 210 & 108 & 72 \\
$\mathbf{1}+\mathbf{2 d}$ & 184 & 107 & 25 \\
& 205 & 107 & 80
\end{tabular}

\section{Acid catalyzed STP}

The polymerization experiments for the TFA catalysis are summarized in Table S3† and Fig. 2. The monomer ratio 1:2 n\% was varied. Optically transparent and homogenous hybrid materials were obtained for the monomers $\mathbf{2 a}, \mathbf{2 b}$ and $\mathbf{2 c}$ with 1 (Table S3†). The transparency of the hybrid material decreases with increasing amount of monomer 2d. Fig. 2 shows the hybrid materials derived from STP of $\mathbf{1}+\mathbf{2 b}$ as an example in comparison to the materials obtained from STP of $1+2 d$.

The effect of silicon alkyl/aryl substituents and monomer ratios of 1 and 2 on the molecular structure of the hybrid materials were studied by solid state NMR spectroscopy. The ${ }^{13} \mathrm{C}-\left\{{ }^{1} \mathrm{H}\right\}$-CP-MAS-NMR spectra show typical signals for phenolic resin and additional signals for the dialkyl(aryl)siloxane units, which can be observed at 28 ppm for the dicyclohexylgroups of monomer 2d, at 115 to $135 \mathrm{ppm}$ for the diphenylgroups of monomer 2c, at 115 to $135 \mathrm{ppm}$ and $0.5 \mathrm{ppm}$ for the phenyl and methyl groups of monomer $2 \mathbf{b}$ and at $0.5 \mathrm{ppm}$ for the dimethyl group of monomer $2 \mathbf{a}$.

Methylene groups of phenolic resin give a signal at 31-36 ppm. The substitution pattern of the phenolic resin can be estimated from the chemical shifts of the aromatic carbons and of the methylene groups. Non-substituted aromatic carbon atoms in the ortho position to the -OR'-group show signals at $115-119 \mathrm{ppm}\left(o, p^{\prime}\right.$-substitution, see signal 4 in Fig. 3A) and in para position at $120-124 \mathrm{ppm}\left(o, o^{\prime}\right.$-substitution, see signal 3 in Fig. 3A). meta Position linkages can be monitored at 127-135 ppm, but they overlap with residual signals from ortho- and para-substituted phenolic carbon atoms

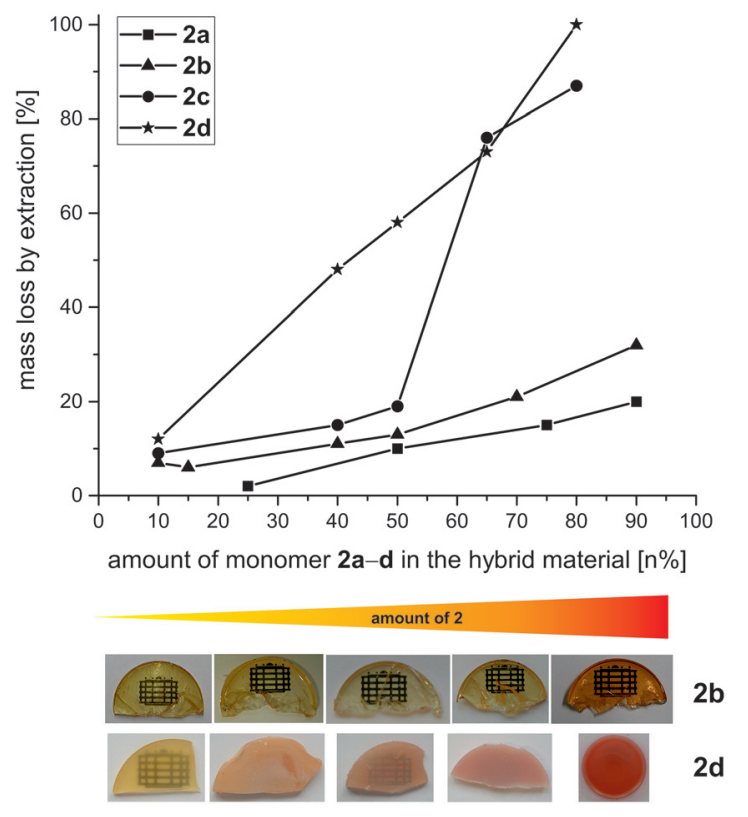

Fig. 2 Mass loss by extraction as a function of the monomer composition $1: 2 a-d$ in the hybrid material obtained from STP using TFA as catalyst and pictures of the monoliths of $1+2 b$ and $1+2 d$ with different monomer ratios derived from TFA catalyzed STP. 
(signals 2 in Fig. 3A). The phenoxy carbon atoms appear at 149-156 ppm for both, $\mathrm{C}_{\text {aryl }}-\mathrm{OH}-$ and $\mathrm{C}_{\text {aryl }}-\mathrm{O}-\mathrm{Si}$-units, and can therefore not be separated. ${ }^{26}$ Although ${ }^{13} \mathrm{C}-\left\{{ }^{1} \mathrm{H}\right\}$ CP-MAS-NMR spectra are not really quantitative, there is a high amount of $o, p^{\prime}$-substitution in the hybrid material as signal 4 is more intense than signal 3 (Fig. 3A), assuming the polarization transfer for all aromatic carbons is in the same order of magnitude.

Additional signals at 58-73 ppm (Fig. 3A) indicate methylene carbon atoms ${ }^{27}$ due to still existing $\mathrm{Si}-\mathrm{O}-\mathrm{CH}_{2}$ groups of the monomers $\mathbf{2 a - d}$. These units are reactive which is shown in DSC measurements of the hybrid materials derived from monomers 2a-c. An exothermic peak due to thermal postcuring is detected (Fig. S9†). In contrast, no exothermic peaks in DSC curves are observed for hybrid materials based on $\mathbf{2 d}$ although there are many sharp signals in the ${ }^{13} \mathrm{C}-\left\{{ }^{1} \mathrm{H}\right\}$ CP-MAS-NMR spectra denoting high mobility in the solid state. These signals originate from unconverted residuals of monomer 2d (signal at $65 \mathrm{ppm}$ ) which is also verified through extraction experiments with DCM (Table S3†). Extraction experiments give the possibility to determine the amount of conversion and to study the structure of side reactions and oligomeric products which are removable from the hybrid material. The mass loss after extraction of all samples (STP of 1 and 2) varies significantly from $6-100 \%$, whereas a clear dependence of the extractable fraction on the monomer ratio can be identified (Fig. 2). The mass loss increases with increasing amount of monomer 2 in the hybrid material which relates to the not crosslinked inorganic compound derived from this monomer.

The inorganic moieties of the hybrid material derived from 1 and 2 can either build two homo polymers of $\mathrm{SiO}_{2}$ and polysiloxane or react with each other to build a copolymer. In case of monomer $2 \mathbf{a}$ the formation of copolymer was proven by solid state NMR spectroscopy and extraction experiments of the hybrid material with acetone and DCM. ${ }^{14}$ Fig. 3B shows ${ }^{29} \mathrm{Si}-\left\{{ }^{1} \mathrm{H}\right\}$-CP-MAS-NMR spectra of hybrid materials obtained from TFA catalyzed STP of $\mathbf{1}$ and 2a-d with signals arising from silicon dioxide and polydialkyl(aryl)siloxane units
$\left(-\mathrm{SiR}^{1} \mathrm{R}^{2} \mathrm{O}^{-}\right)$. Silicon dioxide is characterized through $\mathrm{Q}_{2}$ (-90 ppm), $\mathrm{Q}_{3}$ (-100 ppm) and $\mathrm{Q}_{4}$ (-110 ppm) signals. ${ }^{28,29}$ Whereas $\mathrm{Q}_{4}$ indicates the formation of a complete condensed $\mathrm{SiO}_{2}$ species with four siloxane bridges connecting to the inorganic network, $\mathrm{Q}_{2}$ and $\mathrm{Q}_{3}$ display partly unconverted $\mathrm{Si}-\mathrm{O}-\mathrm{C}$ or $\mathrm{Si}-\mathrm{OH}$ units (see inset in Fig. 3). ${ }^{30}$ D-Structures in the ${ }^{29} \mathrm{Si}$ NMR chemical shift range of $0 \mathrm{ppm}$ to $-45 \mathrm{ppm}$ result from the inorganic moiety of monomer 2 and give information about the degree of condensation and the neighbors of the dialkyl(aryl)subtituted Si-species. The D-signals can be separated in $\mathrm{D}_{2}$ and $\mathrm{D}(\mathrm{Q})$ signals (see inset in Fig. 3). The products obtained from monomers $2 \mathbf{b}$ and $2 \mathbf{c}$ with 1 show both signals. This proves the formation of a copolymer with the $\mathrm{SiO}_{2}$ network because the $\mathrm{D}(\mathrm{Q})$ type of signal occurs if D-type silicon atoms are bound covalently to silica (Q-species).

Extraction of the hybrid materials with DCM reduces the intensity of the $\mathrm{D}_{2}$ signal compared to the $\mathrm{D}(\mathrm{Q})$ signal (Fig. S8†). This is due to the solubility of the polysiloxane homopolymer in the extraction solvent DCM, whereas the polysiloxane cannot be extracted if covalently bound to the silica (= copolymer).

The hybrid material based on monomer $2 \mathbf{d}$ also shows additional sharp signals in the ${ }^{29} \mathrm{Si}$ solid state NMR which relates to the ${ }^{13} \mathrm{C}$ solid state NMR spectrum. After extraction with DCM, only weak $\mathrm{D}_{2}$ and $\mathrm{D}(\mathrm{Q})$ signals remain in the ${ }^{29} \mathrm{Si}$ solid state NMR spectrum indicating low tendency of copolymerization of polydicyclohexylsiloxane (PDHS) with $\mathrm{SiO}_{2}$ and a higher part of oligomers of PDHS (Fig. 4A). No homopolymerization of $\mathbf{2 d}$ to large cycles or high molecular weight PDHS can be noticed which correspondes well with the results of DSC measurements. This confirms the decreasing reactivity of 2 in STP in accordiance to the steric demand of the monomers because monomer $\mathbf{2 d}$ has, compared to monomer 2a, very sterically demanding substituents.

Moreover, hybrid materials derived from 2a-c show similar ratios of $\mathrm{Q}_{2}, \mathrm{Q}_{3}$ and $\mathrm{Q}_{4}$. In case of $\mathbf{2 d}$ a higher amount of $\mathrm{Q}_{2}$ is detected. Monomer $\mathbf{2 d}$ seems to act as a solvent, to dilute the polymerization mixture and to disrupt the TP of $\mathbf{1}$ due to its very low tendency to polymerize.
A

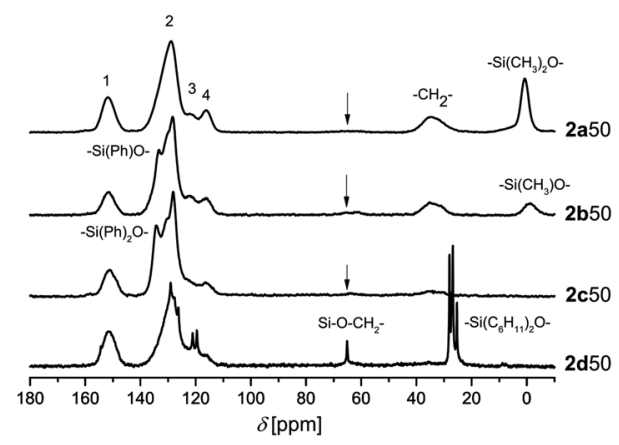

B

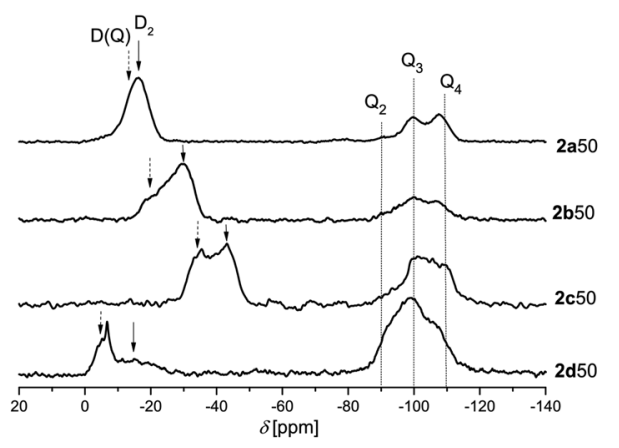

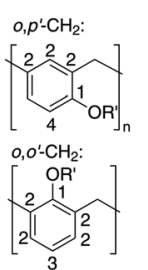

$\mathrm{D}_{2} \quad \mathrm{D}(\mathrm{Q})$

$\left[\mathrm{R}^{1}\right] \mathrm{R}^{1}$

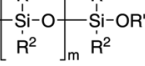

$\mathrm{Q}_{4} \mathrm{Si}(\mathrm{OSi} \equiv)_{4}$

$\mathrm{Q}_{3} \mathrm{Si}(\mathrm{OS} \equiv)_{3} \mathrm{OR}^{\prime \prime}$

$\mathrm{Q}_{2} \mathrm{Si}(\mathrm{OS} \equiv)_{2}(\mathrm{OR} ")_{2}$

$\left.\mathrm{R}^{\prime}=\mathrm{H}, \mathrm{SiO}_{2}-\mathrm{Si}^{1} \mathrm{R}^{2}\right) \mathrm{O}$

$\mathrm{R}^{\prime \prime}=\mathrm{H}, \mathrm{SiO}_{2},-\mathrm{Si}\left(\mathrm{R}^{1} \mathrm{R}^{2}\right) \mathrm{O}-,-\mathrm{CH}_{2}-$

2a: $\mathrm{R}^{1}, \mathrm{R}^{2}=\mathrm{CH}_{3}$

2b: $\mathrm{R}^{1}=\mathrm{CH}_{3}, \mathrm{R}^{2}=$ phenyl

2c: $R^{1}, R^{2}=$ phenyl

2d: $R^{1}, R^{2}=$ cyclohexyl

Fig. 3 A ${ }^{13} \mathrm{C}-\left\{{ }^{1} \mathrm{H}\right\}-\mathrm{CP}-\mathrm{MAS}-\mathrm{NMR}$ spectra and $\mathrm{B}{ }^{29} \mathrm{Si}-\left\{{ }^{1} \mathrm{H}\right\}-\mathrm{CP}-\mathrm{MAS}-\mathrm{NMR}$ spectra of hybrid materials produced from different monomers 2 at a monomer ratio $1: 2$ of $50: 50 \mathrm{n} \%$ (before extraction). 
A

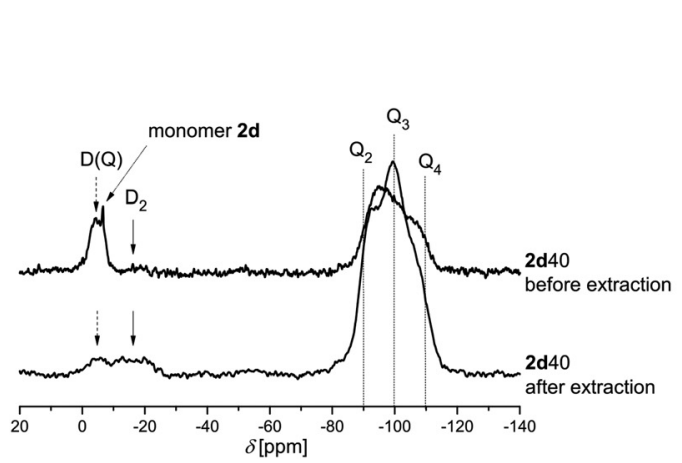

B

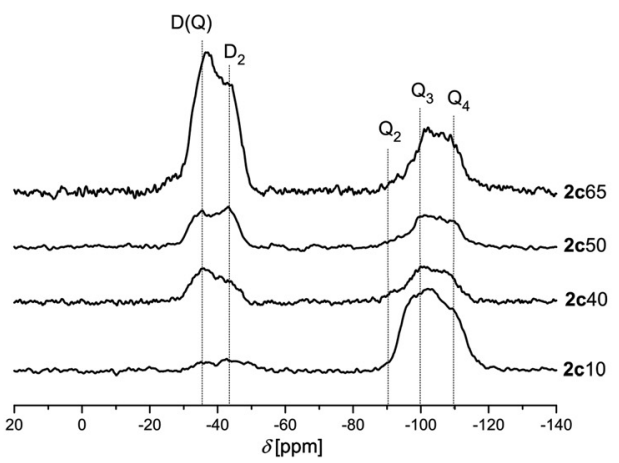

$\mathrm{D}_{2} \quad \mathrm{D}(\mathrm{Q})$

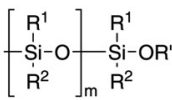

$\mathrm{Q}_{4} \quad \mathrm{Si}(\mathrm{OSi} \equiv)_{4}$

$\mathrm{Q}_{3} \mathrm{Si}(\mathrm{OSi} \equiv)_{3} \mathrm{OR}^{\prime \prime}$

$\mathrm{Q}_{2} \mathrm{Si}(\mathrm{OSi} \equiv)_{2}\left(\mathrm{OR}^{\prime \prime}\right)_{2}$

$\mathrm{R}^{\prime}=\mathrm{H}, \mathrm{C}_{\mathrm{Ary}}$, - -silica-

$R^{\prime \prime}=H, C_{\text {Aryl }},-S i\left(R^{1} R^{2}\right) O-$

2a: $R^{1}, R^{2}=C_{3}$

2b: $R^{1}=\mathrm{CH}_{3}, \mathrm{R}^{2}=$ phenyl

2c: $R^{1}, R^{2}=$ phenyl

2d: $\mathbf{R}^{1}, R^{2}=$ cyclohexyl

Fig. 4 A ${ }^{29} \mathrm{Si}-\left\{{ }^{1} \mathrm{H}\right\}-\mathrm{CP}-\mathrm{MAS}-\mathrm{NMR}$ spectra of the hybrid material $2 \mathrm{~d} 40$ before and after extraction. B ${ }^{29} \mathrm{Si}-\left\{{ }^{1} \mathrm{H}\right\}-\mathrm{CP}-\mathrm{MAS}-\mathrm{NMR}$ spectra of hybrid materials containing monomer $2 \mathrm{c}$ at different monomer ratios ( $\mathrm{n} \%$ ) and a concentration of TFA of $20: 1 \mathrm{n}_{M}: \mathrm{n}_{\text {TFA }}$ (before extraction).

Different monomer ratios used for the synthesis of the hybrid materials are, of course, also reflected in the corresponding intensities of D- and Q-signals in the ${ }^{29} \mathrm{Si}$ solid state NMR spectra (Fig. 4B). The intensity of the D signals increases with increasing amount of monomer 2 in the polymerization mixture which is shown for monomer $2 \mathbf{c}$ as an example. It must be noted that the used cross polarization (CP) technique is not quantitative. However, all measurements were performed under identical experimental conditions and this allows to compare the spectra of the hybrid materials among each other.

\section{Base catalyzed STP}

The polymerization experiments of STP catalyzed with DBU are summarized in Table 2. The following experimental parameters were modified: concentration of catalyst, polymerization time and polymerization temperature. The monomer ratio $1: 2$ was $50: 50 \mathrm{n} \%$ for all experiments.

Compared to TFA catalysis, the polymerizations were performed with reduced catalyst concentrations because otherwise optically inhomogeneous products are formed. ${ }^{31}$ This is

Table 2 DBU catalyzed STP of $2 a-d$ with 1 at a monomer ratio of $2: 1$ $=50: 50[\mathrm{n} \%]$. The naming of the samples is based on the experimental parameters used. The first part of the name represents the molar ratio of monomers to catalyst ( $M: I)$ like $50: 1 \mathrm{n} \%$ is abbreviated as 50 . The next part indicates the specific monomer 2 and the molar ratio of that monomer used in the mixture

\begin{tabular}{lclll}
\hline & $\begin{array}{l}\text { Concentration } \\
\text { of catalyst } \\
\text { Experiment }\end{array}$ & & & \\
& $\mathrm{I}[\mathrm{n} \%]$ & Time & Temperature & $\begin{array}{l}\text { Mass loss by } \\
\text { extraction [\%] }\end{array}$ \\
\hline 50/2a50 & $50: 1$ & $4 \mathrm{~h}$ & $110^{\circ} \mathrm{C}$ & 2 \\
100/2a50 & $100: 1$ & $8 \mathrm{~h}$ & $110^{\circ} \mathrm{C}$ & - \\
300/2a50 & $300: 1$ & $4 \mathrm{~h}$ & $130^{\circ} \mathrm{C}$ & - \\
$50 / 2 \mathbf{b} 50$ & $50: 1$ & $3 \mathrm{~h}$ & $110^{\circ} \mathrm{C}$ & 14 \\
100/2b50 & $100: 1$ & $3 \mathrm{~h}$ & $110^{\circ} \mathrm{C}$ & 25 \\
$50 / 2 \mathbf{c} 50$ & $50: 1$ & $6 \mathrm{~h}$ & $140^{\circ} \mathrm{C}$ & 23 \\
100/2c50 & $100: 1$ & $6 \mathrm{~h}$ & $140^{\circ} \mathrm{C}$ & 28 \\
$50 / 2 \mathbf{d} 50$ & $50: 1$ & $8 \mathrm{~h}$ & $110^{\circ} \mathrm{C}$ & 62
\end{tabular}

due to a mixing problem when adding the catalyst to the monomer mixtures resulting in very high local concentrations of active species at high concentrations of DBU. The concentration of catalyst strongly influences the necessary polymerization time and temperature required to form a hybrid material. And therefore, in comparison to the acid catalyzed STP, the base catalyzed STP demands longer polymerization times and higher polymerization temperatures to form solid hybrid materials. Although the temperature of $110{ }^{\circ} \mathrm{C}$ was found to be a suitable polymerization temperature for all mixtures according to previous DSC measurements (Table 1), the temperature was increased up to $140{ }^{\circ} \mathrm{C}$ for three experiments to ensure solidification of the hybrid materials. The polymerization time differs from 3 to 8 hours. The products are optically transparent and homogenous hybrid materials (Table S4†). Only the material obtained from monomer $\mathbf{2 d}$ is non transparent and flexible due to $2 \mathbf{d}$ showing low tendency to perform TP as shown for TFA catalyzed STP.

The ${ }^{13} \mathrm{C}-\left\{{ }^{1} \mathrm{H}\right\}$-CP-MAS-NMR spectra of the hybrid materials show the typical signals for phenolic resin and dialkyl(aryl) siloxane units, indicating that the molecular structure is similar to the acid catalyzed polymerization. Fig. 5 shows the CP-MAS-NMR spectra of the products obtained from $2 \mathbf{b}$ with different concentration of catalyst as an example. It can be noticed that the ratio of signal 3 and 4 indicating $o, p^{\prime}$ - and $o, o^{\prime}$-substitution is different from the acid catalyzed polymerization. In case of the base catalyzed polymerization $o, o^{\prime}$-substitution is preferred due to higher polymerization temperatures. In case of thermal TP of $\mathbf{1}, o, o^{\prime}$-substitution is clearly obtained in majority. The effect of rearrangement of $o, p^{\prime}$-substitution to $o, o^{\prime}$-substitution at higher temperatures has been described in literature. $^{32}$

The ${ }^{29} \mathrm{Si}-\left\{{ }^{1} \mathrm{H}\right\}$-CP-MAS-NMR spectra of the hybrid materials show D signals for the polydialkyl(aryl)siloxane units and Q signals for the $\mathrm{SiO}_{2}$ network. The $\mathrm{D}$ signals consist of a $\mathrm{D}_{2}$ and a $\mathrm{D}(\mathrm{Q})$ signal which proves copolymerization of the polydialkyl(aryl)siloxane and the silica. Compared to $\mathrm{Q}_{2}$ and $\mathrm{Q}_{3}$ signals, the silica network shows large amounts of $\mathrm{Q}_{4}$ signals. This indicates an early formation of the $\mathrm{SiO}_{2}$ network at an 
A

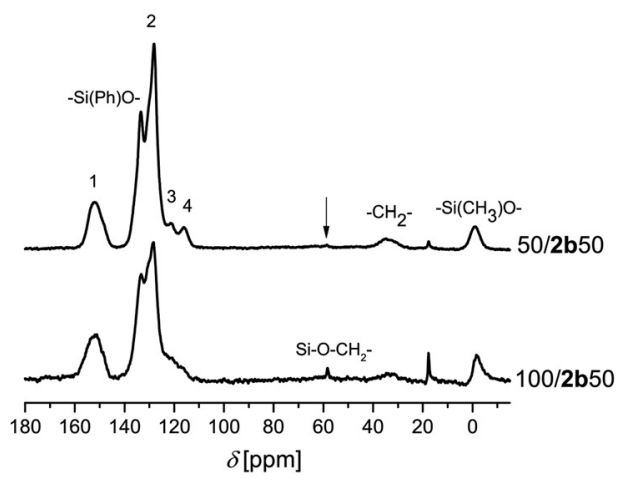

B

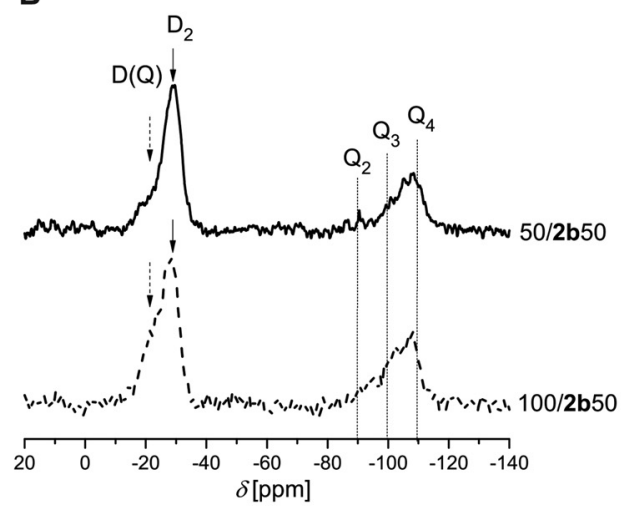

$\begin{array}{lll}\mathrm{D}_{2} & \mathrm{D}(\mathrm{Q})\end{array}$

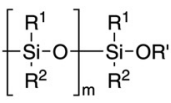

$\mathrm{Q}_{4} \quad \mathrm{Si}(\mathrm{OSi} \equiv)_{4}$

$\mathrm{Q}_{3} \mathrm{Si}(\mathrm{OSi} \equiv)_{3} \mathrm{OR}^{\prime \prime}$

$Q_{2} \quad \mathrm{Si}(\mathrm{OSi} \equiv)_{2}\left(\mathrm{OR}^{\prime \prime}\right)_{2}$

$\mathrm{R}^{\prime}=\mathrm{H}, \mathrm{C}_{\text {Aryl }}$, - silica-

$R^{\prime \prime}=H, C_{\text {Ayll }},-S i\left(R^{1} R^{2}\right) O$

2a: $R^{1}, R^{2}=\mathrm{CH}_{3}$

2b: $\mathrm{R}^{1}=\mathrm{CH}_{3}, \mathrm{R}^{2}=$ phenyl

2c: $\mathrm{R}^{1}, \mathrm{R}^{2}=$ phenyl

2d: $R^{1}, R^{2}=$ cyclohexyl

Fig. $5 \quad A^{13} \mathrm{C}-\left\{{ }^{1} \mathrm{H}\right\}-C P-M A S-N M R$ spectra and $\mathrm{B}^{29} \mathrm{Si}-\left\{{ }^{1} \mathrm{H}\right\}-\mathrm{CP}-\mathrm{MAS}-\mathrm{NMR}$ spectra of hybrid materials produced from monomer $2 \mathrm{~b}$ as an example with different concentration of $\mathrm{DBU}$ (both before extraction).

already low conversion of monomers which can be traced back to the high polymerization temperatures. Nevertheless, many reactive SiOR intermediates remain which can be removed for example by extraction of the hybrid materials (Table S4 $\dagger$ ). The extracts also consist of oligomers of the phenolic resin built during STP. However, a higher concentration of catalyst decreases the mass loss by extraction. Thus, conversion of monomers is enhanced in case of $\mathrm{M}: \mathrm{I}$ of $50: 1 \mathrm{n} \%$ in comparison to $100: 1 \mathrm{n} \%$. For both concentrations of DBU the resulting hybrid materials can be post cured as monitored by DSC measurements which is shown for monomer $2 \mathbf{b}$ (Fig. S11†). Higher concentrations of DBU $(50: 1 \mathrm{n} \%)$ give an exothermic signal starting at $71{ }^{\circ} \mathrm{C}$ during heat treatment. This temperature is typical for the base catalyzed STP of $\mathbf{2 b}$ and $\mathbf{1}$ (Table 1). Thus, small amounts of catalytic active species remain in the hybrid material. In this case, increasing the polymerization time can increase the conversion of the monomers. If a smaller amount of catalyst is applied, the post curing of the material occurs at $168{ }^{\circ} \mathrm{C}$. This temperature is close to the thermal induced polymerization of $\mathbf{2} \mathbf{b}$ and $\mathbf{1}$ which takes place at $200{ }^{\circ} \mathrm{C}$.

\section{Morphology and mechanical properties}

HAADF-STEM analysis of selected samples show fine and dense silicon rich structures with nanoclusters of 1-2 $\mathrm{nm}$ in size. The size of nanostructures can be controlled by the ratio of the two monomers $\mathbf{1}$ and 2, as shown in Fig. 6 for monomer 2a. An increasing amount of monomer $\mathbf{1}$ in the reactant mixture produces smaller nano domains of the final product.

All hybrid materials derived from TFA catalyzed STP of 1 and 2 show similar nanostructures without any clear trend regarding the chemical structure of different monomers $\mathbf{2 a - d}$ (Fig. 7). Electron micrographs of the hybrid material obtained with $\mathbf{1}$ and $\mathbf{2 d}$ in equimolar ratio (2d50) show a special feature within the samples: a very porous structure with holes in the size of several hundred nanometers is visible at lower magnification. The pores result from unconverted monomer $2 \mathbf{d}$ which is dissolved during sample preparation for STEM measure-
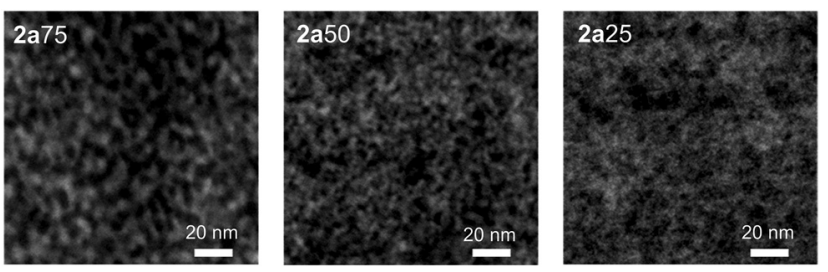

Fig. 6 HAADF-STEM images of hybrid materials derived from 1 and $2 a$ initiated with TFA containing $75 \%, 50 \%$ and $25 \%$ of $2 a$.
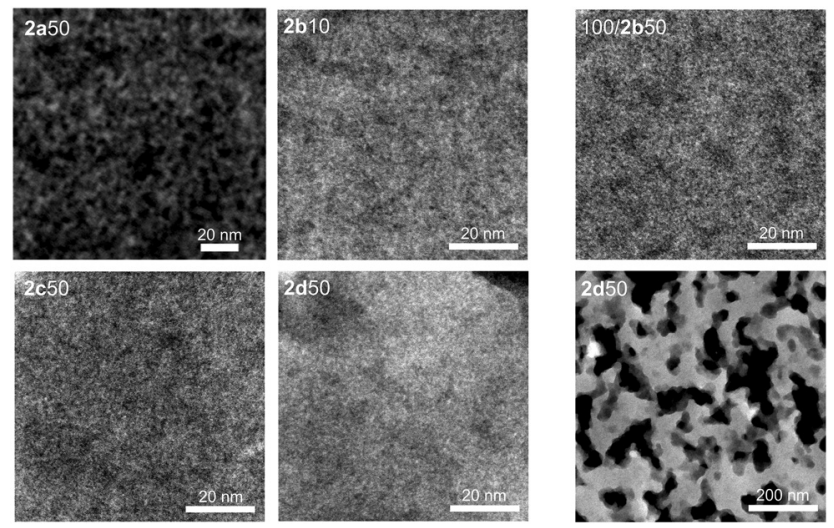

Fig. 7 HAADF-STEM images of hybrid materials derived from STP 1 and 2 using TFA and DBU as catalyst.

ments. The remaining material consists mainly of polymer derived from $\mathbf{1}$ with only small amount of $\mathbf{2 d}$ and shows the nanostructured domains of the phenolic resin and the silica/ oligodicyclohexanesiloxane. The high amount of unconverted monomer 2d and hence the phase separation between monomer and polymer in the $\mathrm{nm}$ scale is the reason for the macroscopic non-transparent monoliths which is also confirmed by the STEM analysis. DBU catalysis of monomers 1 and 2 in equimolar ratio results in hybrid materials which 
typically show nanostructure domains of 1-2 $\mathrm{nm}$ that are similar to acid catalysis.

The Young's modulus and hardness of the surface of the hybrid materials obtained from the acid catalyzed STP of 1 and 2 were measured by nanoindentation analysis (Table S5 $\dagger$ ). The mechanical attributes as a function of the monomer ratio were measured using monomer $\mathbf{2 b}$ as selected example. Fig. 8 illustrates a linear trend of Young's modulus and hardness as function of the 1:2b ratio. Both, Young's modulus and hardness, increase with an increasing amount of monomer 1 in the hybrid material. This trend was also observed for the combination of monomer $\mathbf{1}$ and $\mathbf{2 a}$ in the same order of magnitude. ${ }^{15}$ For this reason, the experimental values were hereafter compared to values of pure PDMS found in the literature.

Whereas pure PDMS samples have a hardness of $28 \mathrm{MPa}^{33}$ and a Young's modulus of about $3.2 \mathrm{GPa}^{32,33}$ the nanocomposites with $\mathrm{SiO}_{2}$, PMPS and phenolic resin exceed this value and reach values of $344.0 \mathrm{MPa}$ and $6.1 \mathrm{GPa}$, respectively. This observation can be explained by an increasing $\mathrm{SiO}_{2}$ content and therefore the total inorganic amount increases, hence stronger formation of $\mathrm{Si}-\mathrm{O}-\mathrm{Si}$ bonds occurs. This results in an increasing resistance to deformation.

For nanometer particle-reinforced polymer composites a Young's modulus of $4.2 \mathrm{GPa}$ and a hardness of $0.25 \times 10^{3} \mathrm{MPa}$ was observed through nanoindentation. ${ }^{34}$ These hybrid materials were prepared by ultraviolet curable technique based on epoxy acrylate as continuous organic phase and silica nanoparticles (5\%) as discontinuous inorganic phase In this case, nanoindentation hardness also increased with the content of nanosilica.

Both, Young's modulus and hardness, decrease with an increasing steric demand of the substituents of 2 for a 1:2 ratio of $50: 50$ (Table S5, Fig. S12 $\dagger$ ). No values were measured for the material TFA/2d50/20 due to its softness. It is assumed that the mechanical properties of the resulting hybrid materials are also influenced by the glass transition temperatures of the polysiloxanes originating from monomer 2 . The $T_{\mathrm{g}}$ increases from PDMS and PMPS to PDPS with increasing size of the substituents at the silicon atom. ${ }^{20}$ However, it could be

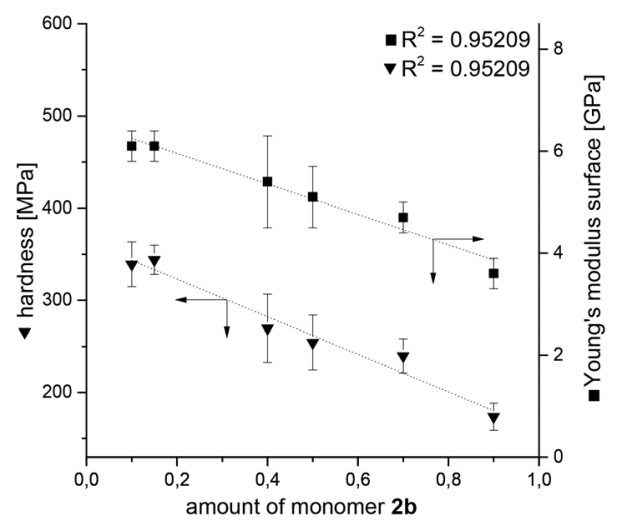

Fig. 8 Hardness and elastic modulus as function of monomer composition of $2 \mathbf{b}: \mathbf{1}$ using TFA as catalyst ( $n=17-28$, error bars cover $3 \sigma$ ). shown that the values for hardness and Young's modulus decrease from PDMS to PDPS. It is important to note, that the nanoindentation was measured at the not extracted hybrid materials. These show a certain amount of monomer or oligomers resulting from an incomplete turnover which are removable and make the material soft. This amount increases from PDMS to PDPS although the materials were treated at the same reaction parameters (Fig. 2). The effect of different organofunctional groups on the hydrolysis reaction at the silicon of silane esters for the acid and base catalysed reaction was studied in the literature. ${ }^{35}$ Herein the reaction rate decreased from methyl- to phenyl- to cyclohexyl-substitution. This is in correlation with the different reactivity of the monomer $\mathbf{2 a - 2 d}$ and hence less turnover during polymerization reaction resulting in less hard hybrid materials.

\section{Conclusion}

Ternary organic hybrid materials consisting of phenolic resin, $\mathrm{SiO}_{2}$ and polysiloxane were synthesized by acid or base catalyzed simultaneous twin polymerization of two twin monomers (1 and 2a-2d). Phenolic resin as organic polymer is formed by both of the monomers, but the different monomers 1 and 2 deliver different inorganic polymers. In case of monomer $\mathbf{2 a}, \mathbf{2} \mathbf{b}$ and $\mathbf{2 c}$ the inorganic fragments react with each other to copolymers. 2d shows only low tendency to form copolymers with $\mathrm{SiO}_{2}$. The corresponding covalent linkage were monitored by ${ }^{29} \mathrm{Si}-\left\{{ }^{1} \mathrm{H}\right\}$-CP-MAS-NMR spectroscopy showing $\mathrm{D}(\mathrm{Q})$ signals. Hence, STP of $\mathbf{1}$ and $\mathbf{2}$ proceeds effective according to the reactivity of the monomers. Increasing steric demand of the substituent in the 2,2'-disubstituted $4 H-1,3,2$ benzodioxasiline lead to low and incomplete conversion. The nature of the catalyst influences the course of reaction and the molecular structure of the products.

According to Sanchez and Mackenzie, the products represent a new class of hybrid materials having one organic polymer mixed on the nanoscale with two inorganic polymers linked through covalent bond (Co-STP). HAADF-STEM analysis verified the dense nanostructure with domains of 1-2 $\mathrm{nm}$ in size. The Young's modulus and hardness at the surface of the hybrid materials can be adjusted by the monomer ratio 1:2.

\section{Acknowledgements}

The authors gratefully acknowledge financial support from the DFG Forschergruppe 1497 and DFG Sp 392/34-2. Thanks are also given to BASF SE for financial support and TEM measurements. Furthermore the authors thank Alexandra Schuberth and Natalia Nier for nanoindentation measurements.

\section{Notes and references}

1 G. Kickelbick, Prog. Polym. Sci., 2003, 28, 83-114. 
2 C. Sanchez, B. Julian, P. Bellville and M. Popall, J. Mater. Chem., 2005, 15, 3559-3592.

3 V. A. Gerasin, E. M. Antipov, V. V. Karbushev, V. G. Kulichikhin, G. P. Karpacheva, R. V. Talroze and Y. V. Kudryavtsev, Russ. Chem. Rev., 2013, 82, 303332.

4 J. D. Mackenzie, J. Sol-Gel Sci. Technol., 1994, 2, 81-86.

5 C. Sanchez and F. Ribot, New J. Chem., 1994, 18, 10071047.

6 H. Müller, P. Rehak, C. Jäger, J. Hartmann, N. Meyer and S. Spange, Adv. Mater., 2000, 12, 1671-1675.

7 S. Grund, A. Seifert, G. Baumann, W. Baumann, G. Marx, M. Kehr and S. Spange, Microporous Mesoporous Mater., 2006, 95, 206-212.

8 C.-L. Chiang, C.-C. Ma, D.-L. Wu and H.-C. Kuan, J. Polym. Sci., Part A: Polym. Chem., 2003, 41, 905-913.

9 B. M. Novak, Adv. Mater., 1993, 6, 422-433.

10 S. Spange and S. Grund, Adv. Mater., 2009, 21, 21112116.

11 S. Spange, P. Kempe, A. Seifert, A. A. Auer, P. Ecorchard, H. Lang, M. Falke, A. Pohlers, M. Hietschold, W. Hoyer, G. Cox, E. Kockrick and S. Kaskel, Angew. Chem., Int. Ed., 2009, 48(44), 8254-8258.

12 L. Ni, N. Moreau, A. Chemtob and C. Croutxé-Barghorn, J. Sol-Gel Sci. Technol., 2012, 64, 500-509.

13 A. Chemtob, C. Belon, C. Croutxé-Barghorn, S. Rigolet, L. Vidal, J. Brendle, J. Mandel and N. Blanchard, Polym. Eng. Sci., 2011, 51, 1466-1475.

14 T. Löschner, A. Mehner, S. Grund, A. Seifert, A. Pohlers, A. Lange, G. Cox, H. J. Hähnle and S. Spange, Angew. Chem., Int. Ed., 2012, 51, 3258.

15 T. Ebert, A. Seifert and S. Spange, Macromol. Rapid Commun., 2015, 36, 1623-1163.

16 P. Kempe, T. Löschner, A. A. Auer, A. Seifert, G. Cox and S. Spange, Chem. - Eur. J., 2014, 20, 8040-8053.

17 P. Kempe, T. Löschner, D. Adner and S. Spange, New J. Chem., 2011, 35, 2735-2739.
18 T. Ebert, G. Cox, E. Sheremet, O. Gordan, D. R. T. Zahn, F. Simon and S. Spange, Chem. Commun., 2012, 48, 98679869.

19 I. Tschernook, J. Prehl and J. Friedrich, Polymer, 2015, 60, 241-251.

20 R. G. Jones, W. Ando and J. Chownjowski, Silicon containing polymers, Springer, 2000, p. 185.

21 M. S. Miran, H. Kinoshita, T. Yasuda, M. A. B. H. Susan and M. Wantanabe, Phys. Chem. Chem. Phys., 2012, 14, 5178-5186.

22 I. Kaljurand, A. Kütt, L. Sooväli, T. Rodima, V. Mäemets, I. Leito and I. A. Koppel, J. Org. Chem., 2005, 70, 10191028.

23 D. MacFarlane, J. Pringle, K. Johansson, S. Forsyth and M. Forsyth, Chem. Commun., 2006, 1905-1917.

24 R. Cragg and M. Nazery, J. Organomet. Chem., 1974, 71, 225-230.

25 R. H. Cragg and R. D. Lane, J. Organomet. Chem., 1978, 154, C6-C8.

26 M. Stevens, Polymer Chemistry: An Introduction, Oxford University Press, New York, Oxford, 1999.

27 R. Rego, P. Adriaensens, R. Carleer and J. Gelan, Polymer, 2004, 45, 33-38.

28 E. Lippmaa, M. Mägi, A. Samoson, G. Engelhardt and A.-R. Grimmer, J. Am. Chem. Soc., 1980, 102, 4889-4893.

29 G. Maciel and D. Sindorf, J. Am. Chem. Soc., 1980, 102, 7607-7608.

30 K. Haraguchi, Y. Usami and Y. Ono, J. Mater. Sci., 1998, 33, 3337-3334.

31 T. Löschner, Ph. D. Thesis, TU Chemnitz, 2013.

32 M. Rahman, R. Dammel and D. Durham, Proc. SPIE - Int. Soc. Opt. Eng., 1994, 2195, 685-695.

33 C. A. Charitidis and E. P. Koumoulos, Plast., Rubber Compos., 2012, 41, 88-93.

34 G. C. Xu, A. Y. Li, L. D. Zhang, X. Y. Yu, T. Xie and G. S. Wu, J. Reinf. Plast. Compos., 2004, 23, 1365-1372.

35 F. D. Osterholtz and E. R. Pohl, J. Adhes. Sci. Technol., 1992, 6, 127-149. 